\title{
A Virtual Academic Unit—the first 10 years
}

\section{A N Williams}

\section{Correspondence to}

Dr A N Williams, Virtual Academic Unit, CDC, Northampton General Hospital, Northampton NN1 5BD, UK; anw@doctors.org.uk

Received 10 December 2014 Accepted 23 January 2015 Published Online First 18 February 2015

\section{CrossMark}

To cite: Williams AN. Arch Dis Child Educ Pract Ed 2015;100:164-165.
"Now is no time to think of what you do not have. Think of what you can do with what there is." Ernest Hemingway ${ }^{1}$

I wish to suggest a structure of a paediatric Virtual Academic Unit (VAU). In Northampton we have run an unfunded VAU from 2004 and have published under the VAU title since 2008, after our first BMJ paper. $^{2}$ It has an entirely internetbased structure which is of considerable potential interest and opportunity given the ongoing revolution in information technology. The VAU is open to all who have an interest in medicine, medical science and medical history/humanities. The VAU demonstrates that anyone can be involved in advancing the care of children through discovery and scholarship, including those traditionally disenfranchised from significant medical/medical humanities research opportunities such as non-medical healthcare professionals, parents, patients and non-teaching hospital healthcare professionals (figure 1).

The 2012 RCPCH Report Turning the Tide: Harnessing the power of child health research recommends the establishment of 'virtual Biomedical Research Units and Centres'. ${ }^{3}$ These are described in adult medicine, but not in paediatrics outside our VAU, in the UK or elsewhere. ${ }^{4}$

Within a generation there has been a transformation as to how education and knowledge are developed and disseminated. It is a living metaphor, but look at how many university library basements previously crypt-like filled with complete sets of unread journals have been revitalised and transformed into $24 \mathrm{~h}$ vibrant computer hubs. Within this context, a $\mathrm{VAU}$, is a concept that allows flexibility, opportunity, ranging widely from international clinical research, to medical history/humanities.

Undertaking research, develops faculties, raises clinical care and keeps the professional job interesting. It is not everyone's cup of tea, but if it is possible to undertake even a small part then it has its own rewards. The intellectual freedom, the subsequent interesting journeys, with conversations and friendships being made and lastly publications are the rewards.

What can a VAU achieve? Pioneering the VAU between 2004 and 2014 my specific aims were:

1. To submit two substantial peer reviewed publications. ${ }^{5} 6$

2. To contribute to an established research group, in my case the Progressive Intellectual and Neurological Deterioration Group, ${ }^{7}$ and became involved in research to ultimately find the underlying cause of neurodegeneration in two of my patients. ${ }^{8}$

3. To become an expert reviewer on an International Charter on Ethical Research Involving Children, also contributing a care report on ethically consenting a child with profound neurodisability due to a progressive neurodegenerative condition. ${ }^{9}$

4. Obtain a $\mathrm{PhD}$ on the history of paediatrics and child health $1550-1750 .{ }^{10}$

5. Create a portfolio of published papers on clinical medicine, medical history/humanities (for a later DM), demonstrating the applied principle of running a VAU. 25689

The specific aims for your VAU will depend on you and your clinical setting.

\section{HOW TO SET UP AND RUN YOUR OWN VAU}

Your ultimate research journey is critically dependent both on the clinical casemix, ie, what comes through your clinic door and the clinical/non-clinical and other networks you can become involved with and set up. A VAU more easily facilitates this worldwide conversation. Other essential top tips are;

- Actively seek for opportunities and develop them.

- Develop local, national and international networks.

- Develop others first, then yourself.

- Give yourself a realistic timescale (5-10 years). 


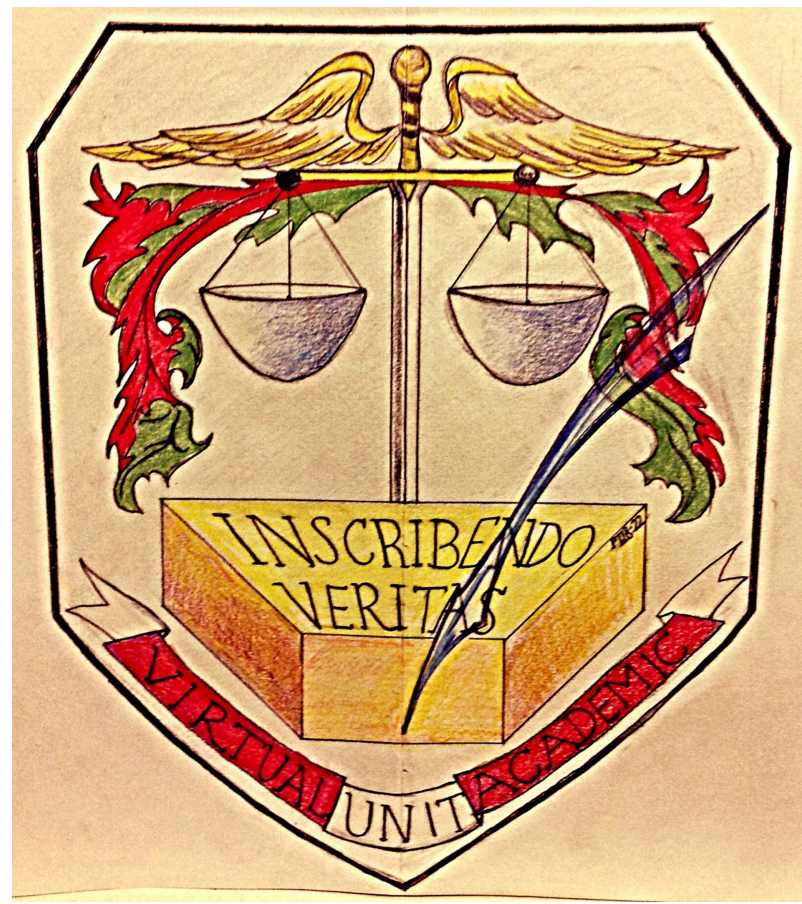

Figure 1 The shield of the Virtual Academic Unit drawn by Mrs Nicola Scudamore.

- Work on more than one project at a time.

- Make maximum use of your study leave time and study leave budget.

I make no claim that a VAU can ever be a complete substitute for a fully funded active tertiary centre research unit, but instead can run alongside it. Indeed I strongly recommend keeping a formal link with a major teaching hospital and if possible collaborating with them. ${ }^{11}$

A VAU has its place and in a present and future environment where resources are continuing to be constrained, a method of working that allows something meaningful to be produced, from where previously nothing could be expected at all. While a lack of funding is restrictive, the total freedom of action is a big plus. ${ }^{12}$ Also with no resources, if you produce anything, that is, a moral victory in itself. Some realistic mechanism translating into sustained funding for VAUs would be very helpful.

So, in conclusion, the trend towards elearning and virtual institutions is only accelerating and the opportunity to make the most of this information technology revolution must be grasped for paediatrics as it already has for other specialities. It is a great shame that talent and opportunity to develop in the light of this revolution is still being denied. Who knows what opportunities to improve healthcare and advances in knowledge would be hindered or indeed lost? A VAU is one potentially important step to redress this.

Competing interests None.

Provenance and peer review Commissioned; internally peer reviewed.

Data sharing statement Google "Virtual Academic Unit" and our other work will be easily accessible.

\section{REFERENCES}

1 Hemingway E. The old man and the sea. Omnibus edition A Farewell to Arms, Death in the Afternoon, The Old Man and the Sea. Jonathan Cape, Publishers, 1992:663.

2 Smith L, Thornton SJ, Reinarz J, et al. Please sir, I want some more ? A Dietetic Analysis of workhouse food contemporary to Oliver Twist. BMJ 2008;337:a2722.

3 Royal College of Paediatrics and Child Health. Turning the Tide: Harnessing the power of child health research. $\mathrm{RCPCH}$, 2012. http://www.rcpch.ac.uk/system/files/protected/page/ Turning\%20the\%20Tide\%20Full\%20Report.pdf (accessed 10 Nov 2014).

4 One such example being the MIHR Cardiovascular Biomedical Research Unit (CVBRU). https://www.google.co.uk/webhp? source $=$ search_app\# $\mathrm{q}=$ virtual + pediatric + research + unit (accessed 19 Jan 2015).

5 Williams AN, Sharma R. Children in Hospitals before there were Children's Hospitals. Pediatrics 2014;134:425-7.

6 Sharma R, Williams AN, Zaw W. Timing of gastrostomy insertion in children with a neurodisability: A cross-sectional study of early versus late intervention. BMJ Open. http://dx.doi. org/doi:10.1136/bmjopen-2012-001793

7 http://www.rcpch.ac.uk/pind (accessed 10 Dec 2014).

8 Eggens VRC, Barth PG, Niermeijer JF, et al. EXOSC3 mutations in pontocerebellar hypoplasia type 1: novel mutations and genotype-phenotype correlations. Orphanet $J$ Rare Dis 2014;9:23.

9 Williams AN. Facilitating future benefit when a participant has a degenerative illness and cannot give consent. In: Graham A, Powell M, Taylor N, et al., eds. Ethical research involving children. Florence: UNICEF Office of Research-Innocenti, 2013:118-9. http://childethics.com/wp-content/uploads/2013/ 11/ERIC_Compendium_Case-Studies_Harms-and-Benefits_ Andrew-Williams.pdf (accessed 13 Nov 2014).

10 Williams AN. "A work of time, accuracy, attention and judgement"-paediatric neurology, neurodisability and child health 1550-1750 [PhD thesis]. UK: University of Birmingham, 2008.

11 http://www.birmingham.ac.uk/research/activity/mds/centres/ histmed/people/fellows.aspx (accessed 11 Nov 2014).

12 Hutchings E, ed. Surely you're joking Mr Feymann. Adventures of a curious character. London: Vantage Books, 1992:346. 